\title{
REVIEW
}

\section{Plasticity After Spinal Cord Injury: Relevance to Recovery and Approaches to Facilitate It}

\author{
Stephen M. Onifer, ${ }^{1,2}$ George M. Smith, ${ }^{1,3}$ and Karim Fouad ${ }^{4}$ \\ ${ }^{1}$ Spinal Cord and Brain Injury Research Center, University of Kentucky, College of Medicine, Lexington, Kentucky 40536-0509; \\ ${ }^{2}$ Department of Anatomy and Neurobiology, University of Kentucky, College of Medicine, Lexington, Kentucky 40536-0098; \\ ${ }^{3}$ Department of Physiology, University of Kentucky, College of Medicine, Lexington, Kentucky 40536-0298; ${ }^{4}$ Rehabilitation \\ Medicine, University of Alberta, Edmonton, Alberta T6G 2G4, Canada
}

\begin{abstract}
Summary: Motor, sensory, and autonomic functions can spontaneously return or recover to varying extents in both humans and animals, regardless of the traumatic spinal cord injury (SCI) level and whether it was complete or incomplete. In parallel, adverse and painful functions can appear. The underlying mechanisms for all of these diverse functional changes are summarized under the term plasticity. Our review will describe what is known regarding this phenomenon after traumatic SCI and focus on its relevance to motor and sensory recovery. Although it is still somewhat speculative, plasticity can be found throughout the neuraxis and includes various changes ranging from alterations in the properties of spared neuronal circuitries, intact or lesioned axon collateral sprouting, and synaptic rearrangements. Furthermore, we will discuss a selection of potential approaches for facilitating plasticity as possible SCI treatments. Because a mechanism underlying
\end{abstract}

spontaneous plasticity and recovery might be motor activity and the related neuronal activity, activity-based therapies are being used and investigated both clinically and experimentally. Additional pharmacological and gene-delivery approaches, based on plasticity being dependent on the delicate balance between growth inhibition and promotion as well as the basic intrinsic growth ability of the neurons themselves, have been found to be effective alone and in combination with activitybased therapies. The positive results have to be tempered with the reality that not all plasticity is beneficial. Therefore, a tremendous number of questions still need to be addressed. Ultimately, answers to these questions will enhance plasticity's potential for improving the quality of life for persons with SCI. Key Words: Spinal cord injury, plasticity, rehabilitation, chondroitin sulfate proteoglycans, Nogo-A, Neurotrophins, gene delivery.

\section{INTRODUCTION}

Devastating long-term dysfunctions occur after traumatic adult spinal cord injury (SCI) and lead to overwhelming physical, psychosocial, and financial hardships. Depending on lesion severity, motor, sensory, and autonomic functions can spontaneously return or recover to varying extents in both humans and animals after SCI. In parallel, adverse and painful functions can begin to occur. Examples of these are described in this issue's article regarding autonomic dysreflexia and spasticity [1]. The underlying mechanisms for all of these diverse functional changes are summarized under

Electronic supplementary material The online version of this article (doi:10.1007/s13311-011-0034-4) contains supplementary material, which is available to authorized users.

Address correspondence and reprint requests to: Stephen M. Onifer, Ph.D., Spinal Cord and Brain Injury Research Center, University of Kentucky, College of Medicine, B457 Biomedical and Biological Sciences Research Building, 741 South Limestone St., Lexington, KY 40536-0509. E-mail: smonif2@email.uky.edu. the term plasticity. Our review will describe what is known about this phenomenon after traumatic injury to the adult spinal cord and focus on its relevance to motor and sensory recovery. Furthermore, we will discuss a selection of potential approaches for facilitating plasticity as possible treatments for traumatic SCI.

\section{SPONTANEOUS FUNCTIONAL RETURN AND RECOVERY AFTER SCI}

Regardless of its level, and whether the injury to the spinal cord was complete or incomplete, plasticity can be found throughout the neuraxis. This includes various changes, ranging from alterations in the properties of spared neuronal circuitries, intact or lesioned axon collateral sprouting, and synaptic rearrangements. Although this plasticity has been associated with spontaneous functional return and recovery [2], the underlying mechanism is still fairly speculative. Furthermore, the 
continuous decline of neuronal function has been reported, and it is unclear whether this should be or is regarded as plasticity (reviewed in Dietz et al. [3]).

The contributions of plasticity to functional return and recovery are hard to discriminate from other possible processes including the recovery from spinal shock and the effect of spontaneous remyelination of spared, but demyelinated axons (eg, see [4]). As for spinal shock, the neuronal mechanism is only vaguely known and could involve the breakdown of membrane potentials, excessive neurotransmitters levels, and the loss of neuromodulators regulating the excitability in the spinal cord [5]. The subsequent recovery could be due to plasticity and/or simple restoration of membrane potentials.

Well-documented examples of plasticity come from the recovery of locomotion in humans and animals following traumatic and experimental SCI. For example, electromyographic (EMG) activity in human leg muscles reappeared during assisted locomotion a few months after complete cervical or thoracic SCI [6]. Importantly for inter-limb coordination, EMG activity in human upper extremity muscles began to be evoked by tibial nerve stimulation months after complete cervical SCI [7]. Comparably, Basso, Beattie, and Bresnahan open field locomotor rating scale scores [8] indicate that slight movement of a rat hind-limb joint occurred by 1 week after thoracic spinal cord transection and that slight-toextensive joint movements were seen thereafter [9]. Similarly, in mice with SCI, the Basso Mouse Scale demonstrates a return of hind-limb movements by 1 week after thoracic spinal cord transection [10]. The onset for return of spontaneous function in both humans and animals after complete SCI could be due to the restoration of motoneuron excitability by constitutive expression of 5-HT2C receptors [11, 12]. Additionally, adaptations in polysynaptic flexor reflexes involved in locomotor circuits $[6,13]$ and synaptic rearrangements may contribute to this first phase of recovery as well [14]. The temporal differences in the spontaneous functional return onset may be due to the relatively higher metabolism of rodents. Also, quadrupedal animals are able to move around their environment soon after injury by using their forelimbs to drag their paralyzed body in contrast to the wheelchair bound and/or medically unstable person with complete SCI who frequently suffers from multiple organ trauma. Because the circuitry connecting skin and muscle primary afferents with spinal interneurons and motoneurons is intact and active after complete SCI [15], sensory information involved in orchestrating stepping movements [16] is transmitted to the animal's spinal cord when the body and joints are moved.

As for incomplete SCI, there was generally more spontaneous recovery in rats by 1 to 2 weeks after transection of their thoracic spinal cords, in which 7 weeks earlier they had undergone contusive injuries, compared with that found in rats with transection alone [9]. Similarly, cats receiving a complete transection following the recovery of a hemisection underwent substantial plasticity, and therefore were immediately capable of supporting their weight on a treadmill [17]. Moreover, plantar stepping that returned to a mouse hind-limb ipsilateral to a thoracic spinal cord hemisection was abolished by delayed, contralateral hemisection [18]. These results indicate that the spinal cord is able to adapt after incomplete injury by mechanisms involving functional redundancy [19], locomotor networks preserved after a second complete lesion [17], spared long-tract axon collateral sprouting [20], sprouting of spinal interneurons even capable of bridging a staggered hemisection [18], and/or adaptations of motoneurons [21] in the thoracolumbar spinal cord caudal to the SCI.

Long-tract axon collateral sprouting is also involved in the plasticity that follows complete axotomy of specific white matter pathways. For example, rat cervical spinal cord dorsal funiculotomies, that is, axotomy of the upper body primary afferents in the dorsal columns fasciculus cuneatus and the lower body primary afferents in the fasciculus gracilis, as well as the dorsal corticospinal tracts, significantly decreased trained reaching for, grasping of, retrieving, and eating food pellets for 2 and 3 weeks, but not at 4 weeks [22]. This spontaneous functional recovery occurring at 4 weeks was mediated by ventral corticospinal tract axon collateral sprouting, as demonstrated by recovery abolishment for 3 weeks when the ventral corticospinal tracts were transected bilaterally at week 4. Furthermore, spontaneous recovery did not occur for 4 weeks when bilateral dorsal columns, dorsal corticospinal tracts, and ventral corticospinal tract transections were combined.

Further evidence of plasticity comes from observations in both human and animal central nervous system (CNS) regions away from the SCI site. We and others have reported spontaneous changes in the size of somatotopic maps of activation occurring in the somatosensory and motor cortices, as well within the brainstem (reviewed in Fouad et al. [2], Raineteau and Schwab [23], and Kaas et al. [24]). Here, as well, axon collateral sprouting appears to be involved. For example, we found that rat hindlimb corticospinal tract axons axotomized in the thoracic spinal cord dorsal funiculus sprouted axons into the cervical spinal cord gray matter [25]. Associated with this was novel forelimb and trunk muscle activity being evoked by hindlimb motor cortex stimulation. Subsequently, it was seen that these collateral axon sprouts innervated both short- and long-propriospinal neurons [26]. Interestingly, the connections with long propriospinal neurons that bridged the lesion and innervated lumbar spinal cord motoneurons persisted and they were found to be electrophysiologically functional with hindlimb 
motor cortex stimulation and hindlimb muscle EMG activity recording. Moreover, recovery of hindlimb placing was associated with axon sprouting. Additionally, Jain et al. [27] observed that complete lesions of the primate cervical spinal cord dorsal columns deactivated the forelimb, trunk, and hind limb representations in the somatosensory cortex. Afferents from the face reactivated these deactivated representations. Associated with this was sprouting of trigeminal primary afferents into the brainstem cuneate nuclei, the target of forelimb and other upper extremity primary afferents [28]. Incomplete lesions of the dorsal columns led to sprouting of spared forelimb primary afferents in the cuneate nuclei and reactivation of forelimb representations [24, 27]. In contrast, reactivation of hind limb representations in the rat somatosensory cortex did not occur following incomplete lesions of the thoracic spinal cord dorsal columns [29]. This suggests species and/or mechanistic differences.

\section{FACILITATING PLASTICITY TO IMPROVE FUNCTIONAL RETURN AND RECOVERY AFTER SCI}

It is now possible to conclude from clinical and experimental evidence that both the adult central and peripheral nervous systems respond to traumatic SCI with plasticity. As for complete SCI, plasticity seems to be maintaining the disconnected spinal cord and possibly preparing it to be re-innervated. In the case of incomplete SCI, plasticity results in recovery to varying extents of functions involving both motor and sensory systems. When plasticity needs to be enhanced to further improve these functions in persons with SCI, additional facilitatory approaches may be extremely useful. Here, we will discuss some activity-based, pharmacological, and gene-delivery approaches that have been found to enhance plasticity. Long-distance, lesioned CNS axon regeneration is not involved due to the time after SCI that it takes [30]. Therefore, approaches that promote longdistance axon regeneration will not be discussed here. However, one is portrayed regarding peripheral nerve grafting in another article in this issue [31].

\section{Activity-based approaches}

As previously discussed, a mechanism underlying spontaneous recovery and plasticity might be motor activity and the related neuronal activity. Triggered by either training or electrical stimulation, neuronal activity results in the up-regulation of brain-derived neurotrophic factor (BDNF) and 3'-5'-cyclic adenosine monophosphate (cAMP) levels, both of which have been implied in plasticity [32-35]. Thus, a logical step to encourage spontaneous recovery is rehabilitative training, which indeed is currently the most successful treatment for SCI.
The breakthrough of rehabilitative training following SCI is based on studies in cats, showing that following complete transection a locomotor pattern could be initiated in the paralyzed hindlimbs [36, 37]. Although no connection to the brain existed, this locomotor "recovery" could be amplified with treadmill training, ultimately resulting in weight-supported stepping on a treadmill $[38,39]$. The promising results of treadmill training in cats were soon translated to clinical applications [40], where it is now viewed as a potent therapy (reviewed in van Hedel and Dietz [41]). Although it has been argued as to whether weight-supported treadmill training is superior to weightsupported over ground locomotor training [42], it is accepted that it significantly aids rehabilitation training.

The effect of locomotor training on recovery following SCI triggered investigations into the underlying mechanisms, and it is now generally accepted that plasticity in the CNS is a major contributor. More recent studies using cervical lesion models, with the functional emphasis on fine motor control of hand/paw function, confirmed these ideas and related plasticity at various levels of the CNS to the recovery of motor function. Not surprisingly, the mechanisms read like a list found under spontaneous plasticity including the up-regulation of growth/plasticity associated factors ([43]; reviewed in Krajacic et al. [35] and Vaynman et al. [44]) and sprouting of lesioned fibers [45], as well as changes in spinal circuitries [17, 38, 39, 46-48], cortical maps [35, 45], and in neuronal properties $[49,50]$.

Although rehabilitative training following SCI is normally associated with beneficial effects on recovery, possible negative consequences also have to be kept in mind. One critical issue that has been identified in stroke research is the negative effect of training very early after injury on functional outcome and lesion/injury size. Although it is generally presumed that an early training onset is most beneficial, there are only few yet controversial reports in animal models of SCI. For example, swim training initiated acutely following thoracic SCI was less efficient compared to a 2-week onset, and it was paralleled by a significantly increased extravasation in and around the injury site [51]. This result has not been found in rats with cervical SCI and different training (reaching) onsets [43]. In a similar scenario, we have only observed negative effects on an untrained task with early onset of training [45], an effect perhaps masked in the functional outcome of the trained task. Another critical complication following SCI is autonomic dysreflexia, which has been proposed to be exaggerated by treadmill training [52], but this is not commonly reported after treadmill training in individuals with SCI.

Another somewhat negative effect of training is the interaction between recovery in a trained task and that of an untrained task. Not surprisingly, training in one task does not necessarily translate into improvements in 
another task [53-56]. Even more surprising are findings that training in one task can even have detrimental effects on another task. For example, cats with complete SCI transections trained to walk on a treadmill had difficulties in standing in contrast to cats trained to stand, which performed worse in walking than untrained cats $[53,56]$. Likewise, rats with cervical SCI trained in a reaching task showed deficits in crossing a horizontal ladder [45] or increased activity induced by environmental enrichment promoted recovery in untrained tasks, but interfered with the training in reaching tasks [57]. These observations suggest that the injured CNS will be rewired task specifically, probably at the cost of other tasks.

\section{Pharmacological and gene-delivery approaches}

Plasticity within the adult CNS is dependent on the delicate balance between growth inhibition and promotion, as well as the basic intrinsic growth ability of the neurons themselves. A number of pharmacological approaches addressing these issues also are being investigated for promoting plasticity after experimental SCI (reviewed in Kwon et al. [58]). In the next paragraphs, we will focus on selected pharmacological approaches that ultimately may be used to treat SCI in patients (Table 1).

Chondroitinase ABC. Chondroitin sulfate proteoglycans (CSPGs), a class of developmentally regulated macromolecules [59], are major components of the CNS extracellular matrix. Furthermore, CSPGs produced by neurons and astrocytes form lattice-like perineuronal nets that shroud adult neuronal cell bodies and proximal dendrites [60,61]. Concentrations of some CSPGs increase in humans and animals not only at the SCI site [62-71] but also rostral [70] and caudal [72] to it.

There have been numerous reports regarding the therapeutic effects on anatomy, electrophysiology, and behavior of altering constitutive and newly synthesized CSPGs in animals after SCI. Bradbury and colleagues were the first to demonstrate that CSPGs inhibited functional recovery after SCI [73]. They intrathecally infused the bacterial enzyme chondroitinase $\mathrm{ABC}$ (chABC) at rat cervical spinal cord dorsal funicultomies to digest chondroitin sulfate glycosaminoglycan chains covalently attached to the CSPG core proteins. This prevented corticospinal tract axon retraction, promoted regeneration of corticospinal tract axons and primary afferents for a short distance beyond the SCI, restored corticospinal tract neurotransmission, and improved both skilled locomotion and walking. These and subsequent results [74-76] further demonstrated that corticospinal tract axons injured in the spinal cord were capable of undergoing regenerative sprouting for short distances, as well as that forelimb functions were improved and hindlimb movements returned following chABC admin- istration. Additionally, collateral sprouting of intact axons has been observed. We found that chABC injections at the brainstem after cervical spinal cord dorsal quadrant lesions promoted collateral sprouting of forepaw primary afferents remaining in the target cuneate nuclei [77]. Moreover, receptive field mapping showed that this sprouting led to more cuneate nuclei neurons responding physiologically to forepaw digits tactile stimulation. Infusing chABC at cervical spinal cord dorsal funicultomies, Barritt et al. [78] confirmed injured corticospinal tract regenerative sprouting within the dorsal funiculi, as well as into gray matter at the SCI and both rostral and caudal to it. They also uncovered intact serotonergic axon collateral sprouting within white matter at the SCI, which was aberrant, and gray matter caudal to it. Aberrant calcitonin gene-related peptide (CGRP)-immunoreactive, primary afferent collateral sprouting within white matter caudal to the SCI was also seen. A further investigation revealed that chABCmediated, aberrant CGRP-containing primary afferent sprouting caudal to a SCI did not lead to increased innervation of dorsal horn nociceptive neurons or the development of thermal hyperalgesia and mechanical allodynia. Tom et al. [79] demonstrated serotonergic axon collateral sprouting throughout gray matter rostral to cervical spinal cord hemisection following a rostral intraspinal $\mathrm{ChABC}$ injection. A caudal intraspinal chABC injection did not promote sprouting caudal to the hemisection, but it did caudal to a cervical spinal cord hemi-contusion, a clinically relevant SCI model. The synaptic component synapsin did not change, and forelimb function during open field and skilled locomotion did not improve, even though chABC-mediated serotonergic axon, and possibly other axon, sprouting occurred.

When combined with other approaches, chABC also has been effective. It has enhanced a variety of cellular treatments in experimental SCI (reviewed in Smith and Onifer [80]). Moreover, chABC administered in Gelfoam at cervical spinal cord hemisection sites combined with intraperitoneal lithium injections led to more ipsilesional forelimb usage [81]. Hindlimb movements returned and locomotion recovery improved after thoracic spinal cord transection and contusion when systemic chABC delivery was combined with intraperitoneal insulin and glucose injections [82] and chABC delivery in Gelfoam at the SCI site was combined with clenbuterol in drinking water [83]. Improved locomotion recovery occurred when an agarose gel scaffold embedded with microtubules was loaded with chABC and neurotrophin-3 (NT-3) and administered at thoracic spinal cord dorsal over-hemisections [84].

Collectively, these anatomical, electrophysiological, and behavior results indicate that reducing inhibitory CSPGs after SCI has the potential of promoting both intact and lesioned axon sprouting, without side effects, 
Table 1. Pharmacological and Gene Delivery Approaches

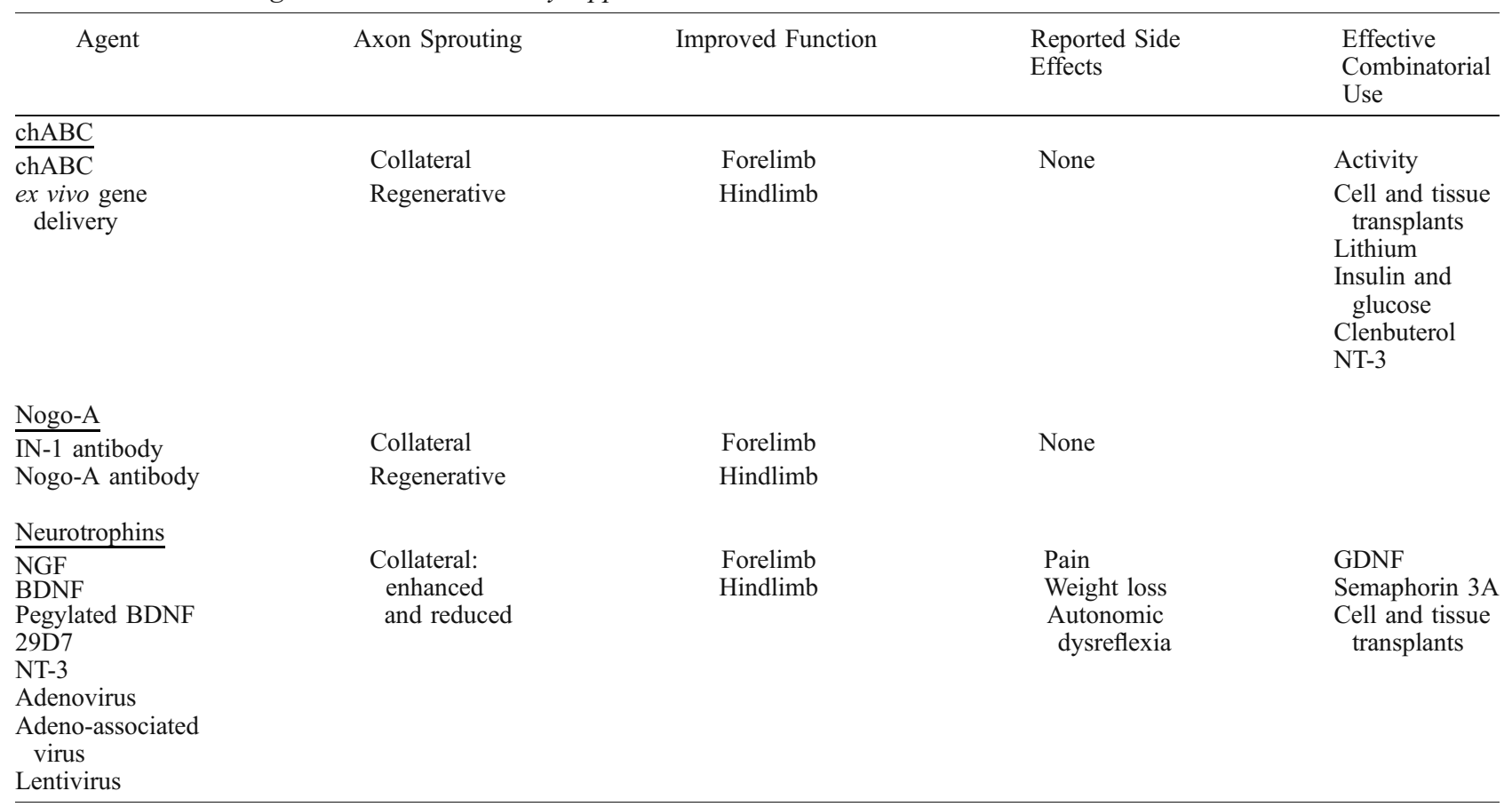

$B D N F$ brain-derived neurotrophic factor, $\operatorname{ch} A B C$ chondroitinase $\mathrm{ABC}, N G F$ nerve growth factor, $N T-3$ neurotrophin-3.

and leading to improved functional recovery when neurons are innervated. Therefore, optimization of this approach is needed. This requires understanding its mechanism of action. Thus far, it is known that injured axons sprout after chABC administration. Importantly, intact axons only sprout where CSPG digestion, degeneration, and denervation occur [57, 78]. This suggests that chABC may modulate immune/inflammatory responses, liberate extracellular matrix-bound facilitatory factors, and overcome interactions between inhibitory CSPGs and extracellular matrix molecules in the injured CNS (reviewed in Crespo et al. [85], Bradbury and Carter [86]). Attenuating the decline in axonal conduction through the SCI site could be involved [87]. Additionally, chABC may reduce growth inhibitory responses in neurons and provide neuroprotection by digesting chondroitin sulfate glycosaminoglycan chains that mediate the interaction between CSPGs and the neuron transmembrane receptor protein tyrosine phosphatase sigma [88, 89].

For translation of this potentially therapeutic approach to the clinic, chABC has been shown to be effective in adults of other species. Faster recovery onset and better performance of skilled locomotor tasks, as well as hindlimb movements occurred in cats when chABC was intrathecally infused after thoracic spinal cord hemisection [90]. Furthermore, alternate chABC delivery strategies are being investigated. Compared with a single, intraspinal chABC injection, bioactive chABC was detected longer and CSPG digestion was more extensive when a fibrin gel containing chABC was topically placed at rat cervical spinal cord dorsal funiculotomies [91]. Chondroitinase $\mathrm{ABC}$ loses most of its activity within a few days at $37^{\circ} \mathrm{C}$ [92]. Thermostabilizing chABC and delivering it in an agarose gel scaffold embedded with microtubules at thoracic spinal cord dorsal over-hemisections improved CSPG digestion compared with a single, intraspinal injection [84]. However, locomotion and thermal sensitivity, as well as primary afferent and serotonergic axon growth, were not improved. Additionally, strategies for chABC administration by mammalian cells instead of in vivo delivery of the bacterial enzyme are also being investigated. We transduced U373 human astocytoma cells with a Tet-On adenoviral vector encoding chAC to secrete enzymatically active chondroitinase that increased neurite outgrowth on CSPGs [93]. Directed mutagenesis of $\mathrm{N}$-glycosylation sites on bacterial chABC facilitated secretion of enzymatically active chondroitinase from transfected COS7 cells, Neu7 cells derived from astrocytes, and neonatal rat cortical astrocytes [94]. These results raise the possibility of ex vivo gene delivery of chABC for experimental, and ultimately clinical, SCI.

Nogo-A. Axon outgrowth inhibition by the CNS myelin-associated proteins Nogo, myelin-associated glycoprotein, and oligodendrocyte myelin glycoprotein is another important target of pharmacological approaches. Like chABC above and neurotrophins below, Nogo-A neutralization has been found to 
enhance both axon collateral and regenerative sprouting (reviewed in Zörner and Schwab [95]). For example, regenerative sprouting of rat corticospinal tract axons into the cervical spinal cord occurred following their lesion in the pyramids of the medulla and intracerebroventricular treatment with the monoclonal antibody IN-1 raised against rat NI-250 myelin protein or Nogo-A [96]. Using the same lesion and treatment, intact corticospinal tract axon collateral sprouting throughout cervical spinal cord gray matter was subsequently observed [97]. Additionally, corticorubral and corticopontine axon collateral sprouting and also cortifugal axon regenerative sprouting occurred. Lesion rats that were treated showed better forelimb reach and pellet retrieval, forelimb use during rope climbing, forelimb rotation during locomotion, and time it took to remove an adhesive sticker from the forepaw. Furthermore, we saw intact rubrospinal tract axon collateral sprouting in the cervical spinal cord when the adult rats were treated intracerebroventricularly with the monoclonal antibody IN-1 following bilateral lesions of corticospinal tract axons in the pyramids $[98,99]$. Some of the sprouted rubrospinal tract axons appeared to be making aberrant connections on to motoneurons. Associated with the anatomical changes was the ability to evoke EMG activity of forelimb muscles with lower electrical stimulation intensities applied to the red nucleus, where the somata of the rubrospinal tract axons are located, and improved forelimb reach and pellet retrieval recovery. Electrical stimulation of the forelimb motor cortices also evoked forelimb EMG activity. Because this could be abolished by injecting muscimol into the red nuclei, it was suggested that the corticorubral pathway was involved. Both corticospinal tract axon collateral and regenerative sprouting as well as improved forelimb reach, grasp, and manual dexterity recovery, were also seen in primates following cervical and thoracic SCIs and Nogo-A antibody treatment [100103], Importantly, adverse effects and pain were not observed in these and many other experiments. Collectively, these results have led to a phase I multicenter clinical trial using intrathecal infusion of human anti-human Nogo-A antibody for treating persons with complete and incomplete cervical and thoracic SCIs (reviewed in Zörner and Schwab [95]). Here again, no adverse effects have been reported.

Neurotrophins. As previously discussed, endogenous neurotrophin concentrations increase in the spinal cord as a result of rehabilitative training after injury. Neurotrophins also have been repeatedly used as extrinsic factors to induce plasticity of either injured or noninjured axons. In most experiments, neurotrophins need to be administered using a mini-pump to supply them for extended periods of time. Gene therapy not only supports long-term expression of neurotrophins, but also this expression can be directed to specific cells, regions, or within simple or complex gradients [104]. Another advantage is many viruses can be retrogradely transported, providing a mechanism for genetic transfer into the spinal cord with minimum trauma. For example, adenovirus induces high levels of neurotrophin expression in many systems, but unfortunately induces a fairly robust immune response if not administered carefully [105]. Injection of adenovirus into lesioned sciatic nerve supports retrograde transport to the spinal cord and subsequent transgene expression in motoneurons without induction of an immune response [106]. This technique has been used to rescue degenerating motoneurons, as well as supporting sprouting of corticospinal tract axons. Thus, this technique not only allows noninvasive production of neurotrophins within the spinal cord, but it also might increase plasticity or synpatogenesis onto this major functional output neuron.

Early studies showed that NT-3 acts to enhance rostral sprouting, but not regeneration, of rat corticospinal tract axons when injected rostrally into thoracic spinal cord dorsal funiculotomies [107]. This study examined only rostral sprouting of injured axons. In a subsequent study, infusion of NT-3 into the cervical or thoracic spinal cords after incomplete lesions of corticospinal tract axons bilaterally in the pyramids reduced collateral sprouting [108]. Zhou et al. [109] lesioned corticospinal tract axons unilaterally in the pyramids and induced retrograde expression of NT-3 within lumbar motor neurons on the denervated side. The expression of NT-3 induced collateral sprouting from the uninjured corticospinal tract axons into the denervated contralateral spinal cord. Contralateral sprouting was only observed after acute injury $[109,110]$ and could be enhanced with secondary application of BDNF or glial cell line-derived neurotrophic factor adenovirus within the motor cortex of the lesioned pathway [111]. Adeno-associated virus also can be retrogradely transported into the spinal cord. It has the added advantage of being endocytosed at nerve terminals, so it is less invasive than adenovirus for inducing transgene expression in spinal cord motoneurons [112, 113]. Using this method, NT-3 motoneuron expression induced sprouting of corticospinal tract axons after cervical dorsal column lesions and limited functional recovery of foot placement [114].

BDNF administration also facilitates plasticity after SCI. BDNF infused into the rat motor cortex enhanced rostral sprouting, but not regeneration, of corticospinal tract axons injured by thoracic spinal cord dorsal funiculotomies [115]. When we applied this approach after thoracic spinal cord dorsal over-hemisection, the collateral sprouting of corticospinal tract axons and innervation of cervical spinal cord propriospinal interneurons we previously observed [25] was enhanced [116]. Intrathecal infusion of BDNF or pegylated BDNF caudal to thoracic spinal cord transection 
or contusive injury similarly promoted cholinergic axon sprouting, stimulated hindlimb air-stepping, and improved both hindlimb joint movements and Basso, Beattie, and Bresnahan open field locomotor rating scale scores [117, 118]. To overcome limitations that would obviate using BDNF clinically, such as weight loss (reviewed in Lebrun et al. [119]) and involvement in pain [120], we recently evaluated a monoclonal antibody (29D7) that has high affinity for TrkB, the receptor for BDNF [121]. Intrathecal 29D7 infusion caudal to cervical spinal cord dorsal quadrant lesions induced corticospinal tract axon sprouting rostral to the SCI and improved contralesional forelimb pellet retrieval recovery. No side effects in a sensory test (plantar heater) were found; however, the drug application was paralleled by an initial weight loss, and when it was discontinued, by a significant weight gain.

Neurotrophin-induced plasticity does not always result in beneficial outcomes and the expression of neurotrophins can induce sprouting of other noninjured pathways. Expression of nerve growth factor (NGF) within the spinal cord induces robust sprouting of endogenous nociceptive pathways leading to persistent intractable pain [122]. When NGF expression within the lumbar spinal cord region was coupled with a complete midthoracic spinal cord transection, the animals developed severe autonomic dysreflexia. This disorder is commonly observed in individuals with spinal cord injuries and involves the conversion of nociceptive input into a sympathetic over-activation [123], and requires sprouting not only of nociceptive afferents but also ascending propriospinal pathways [124]. The sprouting of nociceptive axons can be inhibited by expression of the chemorepulsive molecule semaphorin 3A. Co-expression of semaphorin 3A has been shown to reduce NGF-mediated sprouting, autonomic dysreflexia [123], and allodynia [125].

\section{Combining pharmacological and activity-based approaches}

Chondroitinase ABC. Recently, the effects of combining chABC and activity on forelimb function and locomotion recovery have been examined. GarcíaAlías et al. [57] injected and intrathecally infused chABC at the site of cervical spinal cord dorsal funiculotomies that extended into the gray matter. This improved forelimb pellet retrieval by using the Whishaw apparatus, but not the Staircase apparatus and forelimb placing. Combining the chABC treatments with 1-h daily pellets and seeds retrieval rehabilitation that began 1-week post-SCI improved pellet retrieval in both apparatuses. In contrast to the therapeutic effect of taskspecific rehabilitation, combining the chABC treatments with 1-h daily housing in an enriched environment worsened pellet retrieval on both apparatuses. Combining this general rehabilitation with chABC, however, improved forelimb grip strength compared with chABC with task-specific rehabilitation or chABC treatments alone, which had no effect. Similarly, the combination of chABC and general rehabilitation improved skilled locomotion on a ladder-walking test. Corticospinal tract and serotonergic axon sprouting occurred in rats treated with chABC, however, this was not improved by task-specific or general rehabilitation. Jakeman et al. [126] performed thoracic spinal cord contusions in mice. They injected chABC once into the lumbar enlargement gray matter. CSPGs here have been shown to increase here in the rat after thoracic SCI [72]. The locomotion and sensory recovery of injured mice housed afterwards with running wheels was similar to those treated with chABC, without wheels and injured mice housed with or without wheels. These studies point out that CSPGs in the injured cervical spinal cord limit the effects of task-specific and general rehabilitation on some forelimb functions recovery $[57,126]$. Moreover, CSPGs here may be important for the effect of general rehabilitation of some forelimb functional recovery. It is possible that the ineffectiveness of chABC in the study of Jakeman et al. [126] may have been due to the week delay between the SCI and treatment, the use of a single injection, and also that the axon growth may not have occurred. Acute then repeated chABC treatments that led to axon sprouting had positive effects on some forelimb functions recovery, but not others [57]. Additionally, the chABC injection site may have played a role. Rat locomotion recovers to lesser extents following excitotoxic and contusion SCI at the rostral lumbar spinal cord [127-129]. Wheel running alone also did not improve locomotion recovery; however, task-specific and general rehabilitation alone each had positive, negative, or no effects on forelimb functional recovery [57]. Therefore, these studies also point out a number of critical questions that need to be answered about this potentially therapeutic combinatorial approach. Among them are treatment timing and delivery strategy, rehabilitation type and timing, and outcome measures.

Nogo-A. The combination of Nogo-A antibody and training also has been investigated. Although corticospinal tract axon and serotoninergic axon sprouting occurred in rats with thoracic spinal cord " $T$ " lesions following intrathecal Nogo-A antibody administration, bipedal and quadrupedal body-weight supported treadmill training did not have a synergistic effect on the treadmill kinematics or inclined climbing [130]. However, it has been reported that the combination of intrathecal Nogo-A antibody administration and locomotor training reduced muscle spasms of rats with incomplete SCI and thermal sensitivity [131]. Therefore, these studies suggest that each treatment may be acting through different mechanisms that do not interact. Since Nogo-A antibody treatment is undergoing a 
phase I clinical trial and rehabilitation training is being used clinically, it is important that investigations of the mechanism behind the lack of synergism be performed.

\section{CONCLUDING REMARKS}

Clinical and experimental evidence have convincingly demonstrated that spontaneous plasticity occurs within the adult CNS through a variety of events after traumatic SCI. Additionally, activity-based, pharmacological, and gene-delivery approaches are being found effective, alone and in combination to facilitate plasticity. The positive results have to be tempered with the reality that there are a number of known hurdles. Clearly, not all plasticity is beneficial. Therefore, a tremendous number of questions still need to be addressed in order to harness plasticity. These include the following: whether harmful plasticity can be prevented at the same time when beneficial changes are encouraged, which type of postinjury training is most beneficial and when, why training hinders untrained functions, what doses of pharmacological and gene-delivery approaches should be applied and when, and which combinations will act synergistically. Moreover, promising experimental findings will need to be reproduced before clinical trials are performed. Thus far, it has been difficult for investigators participating in the National Institutes of Health/National Institute of Neurological Disorders and Stroke "Facilities of Research Excellence-Spinal Cord Injury-Replication" program to independently replicate the effects of reported treatments. Finally, the process of translating experimental findings to patients is complicated. Overcoming these hurdles ultimately will allow for using the potential of plasticity to improve the quality of life for persons with SCI.

Acknowledgments: Support for the preparation of the manuscript was provided by the Kentucky Spinal Cord and Head Injury Research Trust (S.M.O.), National Institutes of Health/National Institute of Neurological Disorders and Stroke grant no. R01 NS060784 (G.M.S.), and the Alberta Heritage Foundation for Medical Research (K.F.). Full conflict of interest disclosure is available in the electronic supplemental materials for this article.

\section{REFERENCES}

1. Rabchevsky AG, Kitzman PH. Latest approaches for the treatment of spasticity and autonomic dysreflexia in chronic spinal cord injury. Neurotherapeutics 2010; this issue.

2. Fouad K, Tse A. Adaptive changes in the injured spinal cord and their role in promoting functional recovery. Neurol Res 2008;30:17-27.

3. Dietz V. Behavior of spinal neurons deprived of supraspinal input. Nat Rev Neurol 2010;6:167-174.

4. Onifer SM, Nunn CD, Decker JA, et al. Loss and spontaneous recovery of forelimb evoked potentials in both the adult rat cuneate nucleus and somatosensory cortex following contusive cervical spinal cord injury. Exp Neurol 2007;207:238-247.

5. Dietz V, Colombo G. Recovery from spinal cord injury-underlying mechanisms and efficacy of rehabilitation. Acta Neurochir Suppl 2004;89:95-100.

6. Dietz V, Grillner S, Trepp A, Hubli M, Bolliger M. Changes in spinal reflex and locomotor activity after a complete spinal cord injury: a common mechanism? Brain 2009;132:2196-2205.

7. Calancie B, Molano MR, Broton JG. Interlimb reflexes and synaptic plasticity become evident months after human spinal cord injury. Brain 2002;125:115-1161.

8. Basso DM, Beattie MS, Bresnahan JC. A sensitive and reliable locomotor rating scale for open field testing in rats. J Neurotrauma $1995 ; 12: 1-21$.

9. Basso DM, Beattie MS, Bresnahan JC. Graded histological and locomotor outcomes after spinal cord contusion using the NYU weight-drop device versus transection. Exp Neurol 1996;139:244 256.

10. Basso DM, Fisher LC, Anderson AJ, Jakeman LB, McTigue DM, Popovich PG. Basso Mouse Scale for locomotion detects differences in recovery after spinal cord injury in five common mouse strains. J Neurotrauma 2006;23:635-659.

11. Fouad K, Rank MM, Vavrek R, Murray KC, Sanelli L, Bennett DJ. Locomotion after spinal cord injury depends on constitutive activity in serotonin receptors. J Neurophysiol 2010;104:2975-2984.

12. Murray KC, Nakae A, Stephens MJ, et al. Recovery of motoneuron and locomotor function after spinal cord injury depends on constitutive activity in 5-HT2C receptors. Nat Med 2010;16:694700 .

13. Lavrov I, Gerasimenko YP, Ichiyama RM, et al. Plasticity of spinal cord reflexes after a complete transection in adult rats: relationship to stepping ability. J Neurophysiol 2006;96:1699-1710.

14. Rossignol S. Plasticity of connections underlying locomotor recovery after central and/or peripheral lesions in the adult mammals. Philos Trans R Soc Lond B Biol Sci 2006;361:1647-1671.

15. Valero-Cabré A, Forés J, Navarro X. Reorganization of reflex responses mediated by different afferent sensory fibers after spinal cord transection. J Neurophysiol 2004;91:2838-2848.

16. Pearson KG. Generating the walking gait: role of sensory feedback. Prog Brain Res 2004;143:123-129.

17. Barrière G, Leblond $\mathrm{H}$, Provencher J, Rossignol S. Prominent role of the spinal central pattern generator in the recovery of locomotion after partial spinal cord injuries. J Neurosci 2008;28:3976-3987.

18. Courtine G, Song B, Roy RR, et al. Recovery of supraspinal control of stepping via indirect propriospinal relay connections after spinal cord injury. Nat Med 2008;14:69-74.

19. Loy DN, Magnuson DS, Zhang YP, et al. Functional redundancy of ventral spinal locomotor pathways. J Neurosci 2002;22:315-323.

20. Ballermann M, Fouad K. Spontaneous locomotor recovery in spinal cord injured rats is accompanied by anatomical plasticity of reticulospinal fibers. Eur J Neurosci 2006;23:1988-1996.

21. Boulenguez P, Liabeuf S, Bos R, et al. Down-regulation of the potassium-chloride cotransporter $\mathrm{KCC} 2$ contributes to spasticity after spinal cord injury. Nat Med 2010;16:302-307.

22. Weidner N, Ner A, Salimi N, Tuszynski MH. Spontaneous corticospinal axonal plasticity and functional recovery after adult central nervous system injury. Proc Natl Acad Sci U S A 2001;98:3513-3518.

23. Raineteau O, Schwab ME. Plasticity of motor systems after incomplete spinal cord injury. Nat Rev Neurosci 2001;2:263273.

24. Kaas JH, Qi HX, Burish MJ, Gharbawie OA, Onifer SM, Massey JM. Cortical and subcortical plasticity in the brains of humans, primates, and rats after damage to sensory afferents in the dorsal columns of the spinal cord. Exp Neurol 2008;209:407-416.

25. Fouad K, Pedersen V, Schwab ME, Brösamle C. Cervical sprouting of corticospinal fibers after thoracic spinal cord injury accompanies shifts in evoked motor responses. Curr Biol 2001;11:1766-1770.

26. Bareyre FM, Kerschensteiner M, Raineteau O, Mettenleiter TC, Weinmann O, Schwab ME. The injured spinal cord spontaneously forms a new intraspinal circuit in adult rats. Nat Neurosci 2004;7:269-277. 
27. Jain N, Catania KC, Kaas JH. Deactivation and reactivation of somatosensory cortex after dorsal spinal cord injury. Nature 1997;386:495-498.

28. Jain N, Florence SL, Qi HX, Kaas JH. Growth of new brainstem connections in adult monkeys with massive sensory loss. Proc Natl Acad Sci U S A 2000;97:5546-5550.

29. Jain N, Florence SL, Kaas JH. Limits on plasticity in somatosensory cortex of adult rats: hindlimb cortex is not reactivated after dorsal column section. J Neurophysiol 1995; 73:1537-1546.

30. Cafferty WB, McGee AW, Strittmatter SM. Axonal growth therapeutics: regeneration or sprouting or plasticity? Trends Neurosci 2008;31:215-220.

31. Cote M-P, Amin A, Tom VJ, Houle JD. Peripheral nerve grafts support regeneration after spinal cord injury. Neurotherapeutics 2010 ; this issue.

32. Geremia NM, Gordon T, Brushart TM, Al-Majed AA, Verge VM. Electrical stimulation promotes sensory neuron regeneration and growth-associated gene expression. Exp Neurol 2007;205:347-359.

33. Udina E, Furey M, Busch S, Silver J, Gordon T, Fouad K. Electrical stimulation of intact peripheral sensory axons in rats promotes outgrowth of their central projections. Exp Neurol 2008;210:238-247.

34. Ying Z, Roy RR, Zhong H, Zdunowski S, Edgerton VR, GomezPinilla F. BDNF-exercise interactions in the recovery of symmetrical stepping after a cervical hemisection in rats. Neuroscience 2008;155:1070-1078.

35. Krajacic A, Ghosh M, Puentes R, Pearse DD, Fouad K. Advantages of delaying the onset of rehabilitative reaching training in rats with incomplete spinal cord injury. Eur J Neurosci 2009;29:641-651.

36. Forssberg H, Grillner S, Halbertsma J. The locomotion of the low spinal cat. I. Coordination within a hindlimb. Acta Physiol Scand 1980;108:269-281.

37. Forssberg H, Grillner S, Halbertsma J, Rossignol S. The locomotion of the low spinal cat. II. Interlimb coordination. Acta Physiol Scand 1980;108:283-295.

38. Lovely RG, Gregor RJ, Roy RR, Edgerton VR. Effects of training on the recovery of full-weight-bearing stepping in the adult spinal cat. Exp Neurol 1986;92:421-435.

39. Barbeau H, Rossignol S. Recovery of locomotion after chronic spinalization in the adult cat. Brain Res 1987;412:84-95.

40. Finch L, Barbeau H, Arsenault B. Influence of body weight support on normal human gait: development of a gait retraining strategy. Phys Ther 1991;71:842-855.

41. van Hedel HJ, Dietz V. Rehabilitation of locomotion after spinal cord injury. Restor Neurol Neurosci 2010;28:123-134.

42. Dobkin B, Apple D, Barbeau H, et al. Weight-supported treadmill vs over-ground training for walking after acute incomplete SCI. Neurology 2006;66:484-493.

43. Maier IC, Baumann K, Thallmair M, Weinmann O, Scholl J, Schwab ME. Constraint-induced movement therapy in the adult rat after unilateral corticospinal tract injury. J Neurosci 2008;28:9386-9403.

44. Vaynman S, Gomez-Pinilla F. License to run: exercise impacts functional plasticity in the intact and injured central nervous system by using neurotrophins. Neurorehabil Neural Repair 2005;19:283-295.

45. Girgis J, Merrett D, Kirkland S, Metz GA, Verge V, Fouad K. Reaching training in rats with spinal cord injury promotes plasticity and task specific recovery. Brain 2007;130:2993-3003.

46. Ichiyama RM, Courtine G, Gerasimenko YP, et al. Step training reinforces specific spinal locomotor circuitry in adult spinal rats. J Neurosci 2008;28:7370-7375.

47. de Leon RD, Roy RR, Edgerton VR. Is the recovery of stepping following spinal cord injury mediated by modifying existing neural pathways or by generating new pathways? A perspective. Phys Ther 2001;81:1904-1911.

48. Tillakaratne NJ, de Leon RD, Hoang TX, Roy RR, Edgerton VR, Tobin AJ. Use-dependent modulation of inhibitory capacity in the feline lumbar spinal cord. J Neurosci 2002;22:3130-3143.

49. Petruska JC, Ichiyama RM, Jindrich DL, et al. Changes in motoneuron properties and synaptic inputs related to step training after spinal cord transection in rats. J Neurosci 2007;27:4460-4471.

50. Beaumont E, Kaloustian S, Rousseau G, Cormery B. Training improves the electrophysiological properties of lumbar neurons and locomotion after thoracic spinal cord injury in rats. Neurosci Res 2008;62:147-154.

51. Smith RR, Brown EH, Shum-Siu A, et al. Swim training initiated acutely after spinal cord injury is ineffective and induces extravasation in and around the epicenter. J Neurotrauma 2009;26:1017-1027.

52. Laird AS, Carrive P, Waite PM. Effect of treadmill training on autonomic dysreflexia in spinal cord - injured rats. Neurorehabil Neural Repair 2009;23:910-920.

53. de Leon RD, Hodgson JA, Roy RR, Edgerton VR. Locomotor capacity attributable to step training versus spontaneous recovery after spinalization in adult cats. J Neurophysiol 1998;79:1329-1340.

54. Grasso R, Ivanenko YP, Zago M, Molinari M, Scivoletto G, Lacquaniti F. Recovery of forward stepping in spinal cord injured patients does not transfer to untrained backward stepping. Exp Brain Res 2004;157:377-382.

55. Smith RR, Shum-Siu A, Baltzley R, et al. Effects of swimming on functional recovery after incomplete spinal cord injury in rats. J Neurotrauma 2006;23:908-919.

56. Bigbee AJ, Crown ED, Ferguson AR, et al. Two chronic motor training paradigms differentially influence acute instrumental learning in spinally transected rats. Behav Brain Res 2007; 180:95-101

57. García-Alías G, Barkhuysen S, Buckle M, Fawcett JW. Chondroitinase $\mathrm{ABC}$ treatment opens a window of opportunity for taskspecific rehabilitation. Nat Neurosci 2009;12:1145-1151

58. Kwon BK, Okon EB, Plunet W, et al. A systematic review of directly applied biologic therapies for acute spinal cord injury. J Neurotrauma 2010;27:1-22.

59. Steindler DA. Glial boundaries in the developing nervous system. Annu Rev Neurosci 1993;16:445-470.

60. Golgi C. Intorno all'origine del quarto nervo cerebrale e una questione isto-fisiologica che a questo argomento si collega. Rendiconti della Reale Accademia Del Lincei 1893;2:379-389.

61. Kwok JC, Carulli D, Fawcett JW. In vitro modeling of perineuronal nets: hyaluronan synthase and link protein are necessary for their formation and integrity. J Neurochem 2010;114:1447-1459.

62. Lemons ML, Howland DR, Anderson DK. Chondroitin sulfate proteoglycan immunoreactivity increases following spinal cord injury and transplantation. Exp Neurol 1999;160:51-65.

63. Bruce JH, Norenberg MD, Kraydieh S, Puckett W, Marcillo A, Dietrich D. Schwannosis: role of gliosis and proteoglycan in human spinal cord injury. J Neurotrauma 2000;17:781-788.

64. Lemons ML, Sandy JD, Anderson DK, Howland DR. Intact aggrecan and fragments generated by both aggrecanse and metalloproteinase-like activities are present in the developing and adult rat spinal cord and their relative abundance is altered by injury. $\mathrm{J}$ Neurosci 2001;21: 4772-4781.

65. Jones LL, Yamaguchi Y, Stallcup WB, Tuszynski MH. NG2 is a major chondroitin sulfate proteoglycan produced after spinal cord injury and is expressed by macrophages and oligodendrocyte progenitors. J Neurosci 2002;22:2792-2803.

66. Jones LL, Margolis RU, Tuszynski MH. The chondroitin sulfate proteoglycans neurocan, brevican, phosphacan, and versican are differentially regulated following spinal cord injury. Exp Neurol 2003;182:399-411

67. Tang X, Davies JE, Davies SJ. Changes in distribution, cell associations, and protein expression levels of NG2, neurocan, phosphacan, brevican, versican V2, and tenascin-C during acute to chronic maturation of spinal cord scar tissue. J Neurosci Res 2003; 71:427-444

68. Buss A, Brook GA, Kakulas B, Martin D, Franzen R, Schoenen J, et al. Gradual loss of myelin and formation of an astrocytic scar during Wallerian degeneration in the human spinal cord. Brain 2004; $127: 34-44$.

69. Iaci JF, Vecchione AM, Zimber MP, Caggiano AO. Chondroitin sulfate proteoglycans in spinal cord contusion injury and the effects of chondroitinase treatment. J Neurotrauma 2007;24:1743-1759.

70. Massey JM, Amps J, Viapiano MS, et al. Increased chondroitin sulfate proteoglycan expression in denervated brainstem targets following spinal cord injury creates a barrier to axonal regeneration overcome by chondroitinase $\mathrm{ABC}$ and neurotrophin-3. Exp Neurol 2008;209:426-445 
71. Buss A, Pech K, Kakulas BA, et al. NG2 and phosphacan are present in the astroglial scar after human traumatic spinal cord injury. BMC Neurol 2009;9:32.

72. Qi ML, Wakabayashi Y, Enomoto M, Shinomiya K. Changes in neurocan expression in the distal spinal cord stump following complete cord transection: a comparison between infant and adult rats. Neurosci Res 2003;45:181-188.

73. Bradbury EJ, Moon LD, Popat RJ, et al. Chondroitinase ABC promotes functional recovery after spinal cord injury. Nature 2002;416:636-640.

74. García-Alías G, Lin R, Akrimi SF, Story D, Bradbury EJ, Fawcett JW. Therapeutic time window for the application of chondroitinase $\mathrm{ABC}$ after spinal cord injury. Exp Neurol 2008;210:331-338.

75. Iseda T, Okuda T, Kane-Goldsmith N, et al. Single, high-dose intraspinal injection of chondroitinase reduces glycosaminoglycans in injured spinal cord and promotes corticospinal axonal regrowth after hemisection but not contusion. J Neurotrauma 2008;25:334349.

76. Huang WC, Kuo WC, Cherng JH, et al. Chondroitinase ABC promotes axonal re-growth and behavior recovery in spinal cord injury. Biochem Biophys Res Commun 2006;349:963-968.

77. Massey JM, Hubscher CH, Wagoner MR, et al. Chondroitinase $\mathrm{ABC}$ digestion of the perineuronal net promotes functional collateral sprouting in the cuneate nucleus after cervical spinal cord injury. J Neurosci 2006;26:4406-4414.

78. Barritt AW, Davies M, Marchand F, et al. Chondroitinase ABC promotes sprouting of intact and injured spinal systems after spinal cord injury. J Neurosci 2006;26:10856-10867.

79. Tom VJ, Kadakia R, Santi L, Houlé JD. Administration of chondroitinase $\mathrm{ABC}$ rostral or caudal to a spinal cord injury site promotes anatomical but not functional plasticity. J Neurotrauma 2009;26:2323-2333.

80. Smith GM, Onifer SM. Construction of pathways to promote axon growth within the adult central nervous system. Brain Res Bull 2011;84:300-305.

81. Yick LW, So KF, Cheung PT, Wu WT. Lithium chloride reinforces the regeneration-promoting effect of chondroitinase $\mathrm{ABC}$ on rubrospinal neurons after spinal cord injury.J Neurotrauma 2004;21:932-943.

82. Yang YG, Jiang DM, Quan ZX, Ou YS. Insulin with chondroitinase $\mathrm{ABC}$ treats the rat model of acute spinal cord injury. J Int Med Res 2009;37:1097-1107.

83. Bai F, Peng H, Etlinger JD, Zeman RJ. Partial functional recovery after complete spinal cord transection by combined chondroitinase and clenbuterol treatment. Pflugers Arch 2010;460:657-666.

84. Lee H, McKeon RJ, Bellamkonda RV. Sustained delivery of thermostabilized chABC enhances axonal sprouting and functional recovery after spinal cord injury. Proc Natl Acad Sci U S A 2010;107:3340-3345.

85. Crespo D, Asher RA, Lin R, Rhodes KE, Fawcett JW. How does chondroitinase promote functional recovery in the damaged CNS? Exp Neurol 2007;206:159-171.

86. Bradbury EJ, Carter LM. Manipulating the glial scar: Chondroitinase $\mathrm{ABC}$ as a therapy for spinal cord injury. Brain Res Bull 2011;84:306-316.

87. Hunanyan AS, García-Alías G, Alessi V, et al. Role of chondroitin sulfate proteoglycans in axonal conduction in Mammalian spinal cord. J Neurosci 2010;30:7761-7769.

88. Shen Y, Tenney AP, Busch SA, et al. PTPsigma is a receptor for chondroitin sulfate proteoglycan, an inhibitor of neural regeneration. Science 2009;326:592-596.

89. Fry EJ, Chagnon MJ, López-Vales R, Tremblay ML, David S. Corticospinal tract regeneration after spinal cord injury in receptor protein tyrosine phosphatase sigma deficient mice. Glia 2010;58:423-433.

90. Tester NJ, Howland DR. Chondroitinase ABC improves basic and skilled locomotion in spinal cord injured cats. Exp Neurol 2008;209:483-496.

91. Hyatt AJ, Wang D, Kwok JC, Fawcett JW, Martin KR. Controlled release of chondroitinase $\mathrm{ABC}$ from fibrin gel reduces the level of inhibitory glycosaminoglycan chains in lesioned spinal cord. J Control Release 2010;147:24-29.
92. Tester NJ, Plaas AH, Howland DR. Effect of body temperature on chondroitinase ABC's ability to cleave chondroitin sulfate glycosaminoglycans. J Neurosci Res 2007;85:1110-1118.

93. Curinga GM, Snow DM, Mashburn C, et al. Mammalianproduced chondroitinase AC mitigates axon inhibition by chondroitin sulfate proteoglycans. J Neurochem 2007;102:275-288.

94. Muir EM, Fyfe I, Gardiner S, et al. Modification of Nglycosylation sites allows secretion of bacterial chondroitinase ABC from mammalian cells. J Biotechnol 2010;145:103-110

95. Zörner B, Schwab ME. Anti-Nogo on the go: from animal models to a clinical trial. Ann N Y Acad Sci 2010;1198:E22-E34.

96. Raineteau O, Z'Graggen WJ, Thallmair M, Schwab ME. Sprouting and regeneration after pyramidotomy and blockade of the myelin-associated neurite growth inhibitors NI 35/250 in adult rats. Eur J Neurosci 1999;11:1486-490.

97. Thallmair M, Metz GA, Z'Graggen WJ, Raineteau O, Kartje GL, Schwab ME. Neurite growth inhibitors restrict plasticity and functional recovery following corticospinal tract lesions. Nat Neurosci 1998;1:124-131.

98. Raineteau O, Fouad K, Noth P, Thallmair M, Schwab ME. Functional switch between motor tracts in the presence of the $\mathrm{mAb} \mathrm{IN}-1$ in the adult rat. Proc Natl Acad Sci U S A 2001;98:6929-6934

99. Raineteau O, Fouad K, Bareyre FM, Schwab ME. Reorganization of descending motor tracts in the rat spinal cord. Eur J Neurosci 2002;16:1761-1771

100. Fouad K, Klusman I, Schwab ME. Regenerating corticospinal fibers in the Marmoset (Callitrix jacchus) after spinal cord lesion and treatment with the anti-Nogo-A antibody IN-1. Eur J Neurosci 2004;20:2479-2482.

101. Freund P, Schmidlin E, Wannier T, et al. Nogo-A-specific antibody treatment enhances sprouting and functional recovery after cervical lesion in adult primates. Nat Med 2006;12:790792.

102. Freund P, Wannier T, Schmidlin E, et al. Anti-Nogo-A antibody treatment enhances sprouting of corticospinal axons rostral to a unilateral cervical spinal cord lesion in adult macaque monkey. J Comp Neurol 2007;502:644-659.

103. Freund P, Schmidlin E, Wannier T, et al. Anti-Nogo-A antibody treatment enhances sprouting of corticospinal axons rostral to a unilateral cervical spinal cord lesion in adult macaque monkey. Eur J Neurosci 2009;29:983-996.

104. Curinga G, Smith GM. Molecular/genetic manipulation of extrinsic axon guidance factors for CNS repair and regeneration. Exp Neurol 2008;209:333-342.

105. Smith GM, Romero MI. Adenoviral-mediated gene transfer to enhance neuronal survival, growth, and regeneration. J Neurosci Res 1999;55:147-157.

106. Baumgartner BJ, Shine HD. Targeted transduction of CNS neurons with adenoviral vectors carrying neurotrophic factor genes confers neuroprotection that exceeds the transduced population. J Neurosci 1997;17:6504-6511.

107. Schnell L, Schneider R, Kolbeck R, Barde YA, Schwab ME. Neurotrophin-3 enhances sprouting of corticospinal tract during development and after adult spinal cord lesion. Nature 1994;367:170-173.

108. Hagg T, Baker KA, Emsley JG, Tetzlaff W. Prolonged local neurotrophin-3 infusion reduces ipsilateral collateral sprouting of spared corticospinal axons in adult rats. Neuroscience 2005; $130: 875-887$.

109. Zhou L, Baumgartner BJ, Hill-Felberg SJ, McGowen LR, Shine HD. Neurotrophin-3 expressed in situ induces axonal plasticity in the adult injured spinal cord. J Neurosci 2003;23:1424-1431.

110. Chen Q, Zhou L, Shine HD. Expression of neurotrophin-3 promotes axonal plasticity in the acute but not chronic injured spinal cord. J Neurotrauma 2006;23:1254-1260.

111. Zhou L, Shine HD. Neurotrophic factors expressed in both cortex and spinal cord induce axonal plasticity after spinal cord injury. $\mathrm{J}$ Neurosci Res 2003;74:221-226.

112. Kaspar BK, Erickson D, Schaffer D, Hinh L, Gage FH, Peterson DA. Targeted retrograde gene delivery for neuronal protection. Mol Ther 2002;5:50-56. 
113. Kaspar BK, Lladó J, Sherkat N, Rothstein JD, Gage FH. Retrograde viral delivery of IGF-1 prolongs survival in a mouse ALS model. Science 2003;301:839-842.

114. Fortun J, Puzis R, Pearse DD, Gage FH, Bunge MB. Muscle injection of AAV-NT3 promotes anatomical reorganization of CST axons and improves behavioral outcome following SCI. J Neurotrauma 2009;26:941-953.

115. Hiebert GW, Khodarahmi K, McGraw J, Steeves JD, Tetzlaff W. Brain-derived neurotrophic factor applied to the motor cortex promotes sprouting of corticospinal fibers but not regeneration into a peripheral nerve transplant. J Neurosci Res 2002;69:160-168.

116. Vavrek R, Girgis J, Tetzlaff W, Hiebert GW, Fouad K. BDNF promotes connections of corticospinal neurons onto spared descending interneurons in spinal cord injured rats. Brain 2006;129:1534-1545.

117. Jakeman LB, Wei P, Guan Z, Stokes BT. Brain-derived neurotrophic factor stimulates hindlimb stepping and sprouting of cholinergic fibers after spinal cord injury. Exp Neurol 1998;154:170-184.

118. Ankeny DP, McTigue DM, Guan Z, et al. Pegylated brain-derived neurotrophic factor shows improved distribution into the spinal cord and stimulates locomotor activity and morphological changes after injury. Exp Neurol 2001;170:85-100.

119. Lebrun B, Bariohay B, Moyse E, Jean A. Brain-derived neurotrophic factor (BDNF) and food intake regulation: a mini-review. Auton Neurosci 2006;126-127:30-38

120. Suter MR, Wen YR, Decosterd I, Ji RR. Do glial cells control pain? Neuron Glia Biol 2007;3:255-268

121. Fouad K, Vavrek R, Cho S. A TrkB antibody agonist promotes plasticity following cervical spinal cord injury in adult rats. J Neurotrauma 2010;in press.

122. Romero MI, Rangappa N, Li L, Lightfoot E, Garry MG, Smith GM. Extensive sprouting of sensory afferents and hyperalgesia induced by conditional expression of nerve growth factor in the adult spinal cord. J Neurosci 2000;20:4435-4445.
123. Cameron AA, Smith GM, Randall DC, Brown DR, Rabchevsky AG. Genetic manipulation of intraspinal plasticity after spinal cord injury alters the severity of autonomic dysreflexia. J Neurosci 2006;26:2923-2932.

124. Hou S, Duale H, Cameron AA, Abshire SM, Lyttle TS, Rabchevsky AG. Plasticity of lumbosacral propriospinal neurons is associated with the development of autonomic dysreflexia after thoracic spinal cord transection. J Comp Neurol 2008;509:382399.

125. Tang XQ, Tanelian DL, Smith GM. Semaphorin3A inhibits nerve growth factor-induced sprouting of nociceptive afferents in adult rat spinal cord. J Neurosci 2004;24:819-827.

126. Jakeman LB, Hoschouer EL, Basso DM. Injured mice at the gym: review, results and considerations for combining chondroitinase and locomotor exercise to enhance recovery after spinal cord injury. Brain Res Bull 2011;84:317-326.

127. Magnuson DS, Trinder TC, Zhang YP, Burke D, Morassutti DJ, Shields CB. Comparing deficits following excitotoxic and contusion injuries in the thoracic and lumbar spinal cord of the adult rat. Exp Neurol 1999;156:191-204.

128. Hadi B, Zhang YP, Burke DA, Shields CB, Magnuson DS Lasting paraplegia caused by loss of lumbar spinal cord interneurons in rats: no direct correlation with motor neuron loss. J Neurosurg 2000;93:266-275.

129. Magnuson DS, Lovett R, Coffee C, et al. Functional consequences of lumbar spinal cord contusion injuries in the adult rat. J Neurotrauma 2005;22:529-543.

130. Maier IC, Ichiyama RM, Courtine G, et al. Differential effects of anti-Nogo-A antibody treatment and treadmill training in rats with incomplete spinal cord injury. Brain 2009;132:14261440 .

131. Gonzenbach RR, Gasser P, Zörner B, Hochreutener E, Dietz $\mathrm{V}$, Schwab ME. Nogo-A antibodies and training reduce muscle spasms in spinal cord-injured rats. Ann Neurol 2010;68:48-57. 